\title{
TRADICIONES COMUNES, INFLUENCIAS RECÍPROCAS Y PASEOS COMPARTIDOS: ENRIQUE VILA-MATAS Y LA LITERATURA MEXICANA
}

\author{
COMMON TRADITIONS, RECIPROCAL INFLUENCES AND SHARED RIDES:
} ENRIQUE VILA-MATAS AND MEXICAN LITERATURE

Teresa Gónzalez ArCe

Universidad de Guadalajara (México) teresa.gonzalezarce@redudg.udg.mx

\begin{abstract}
Resumen: La escritura de Enrique Vila-Matas está hermanada con la reelaboración que los autores latinoamericanos han hecho del ensayismo europeo, arraigado todavía en las figuras de Bacon y Montaigne. La tradición del ensayo personal confluye en las letras contemporáneas con los mecanismos novelísticos y lanza al canon hispánico géneros limítrofes, híbridos de definición vacilante que cuestionan la verdad acerca de la realidad y la ficción. Vila-Matas sigue los pasos de escritores como Robert Walser, William Hazlitt y Sergio Pitol, y es a su vez seguido muy de cerca y en diálogo vivo por la ensayística mexicana actual, representada por plumas como las de Luigi Amara y Valeria Luiselli. Este artículo explora la forma en que Vila-Matas mezcla recursos del ensayo y la novela, así como su asimilación de los principios de la vida imaginaria analizando su literatura en el contexto de una tradición que surge en Francia, se arraiga en Inglaterra y es reconfigurada actualmente por la escritura hispánica.
\end{abstract}

PAlabras Clave: Enrique Vila-Matas; Valeria Luiselli; Luigi Amara; ensayo personal; vida imaginaria; novela ensayo; ensayo mexicano; ensayo contemporáneo

ABSTRACT: Enrique Vila-Mata's writing is closely linked to latin american author's re-elaboration of the european essay, which still has its roots in the works of Bacon and Montaigne. Personal essay writing, in contemporary literature, is joint with novel-writing devices and thus gives rise in canon to unsteady, cross-bred, hybrid genres, which call the truth of reality and fiction into question. Vila-Matas follows the steps of writers such as Robert Walser, William Hazlitt and Sergio Pitol while being himself followed by current mexican writers such as Luigi Amara and Valeria Luiselli. This paper looks into the way Vila-Matas merges devices from novel and essay, as well as his uptake of imaginary life principles by analys- 
ing his literature in the context of a tradition that was born in France, took root in England and is at present being reshaped by hispanic writing.

KeYwords: Enrique Vila-Matas; Valeria Luiselli; Luigi Amara; Personal Essay; Imaginary Life; Novel; Essay; Mexican Essay; Contemporary Essay

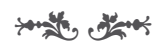

La obra de Enrique Vila-Matas se ha caracterizado por transitar por caminos radicalmente opuestos a la Gran Novela realista del siglo XIX, desmontando sus convenciones por medio de la incorporación de géneros varios en una escritura híbrida, fragmentaria e inacabada que da cuenta de un sujeto desarticulado, mestizo y cambiante (Castro 2016: 473-474). Tanto los estudiosos de su obra como el propio autor han enfatizado igualmente que uno de estos caminos ha sido el del mestizaje de la novela con el ensayo, rumbo decisivo en el proceso de reinvención genérica que inscribe plenamente al autor en una tradición representada por escritores tan preciados para él como Laurence Sterne, Robert Walser o W. G. Sebald.

En este crisol que es la escritura de Vila-Matas, sin embargo, encontramos también otros géneros y subgéneros que, sin ser propiamente ensayísticos, se ubican en el orbe de las escrituras del yo, o pueden ser entendidos y estudiados a partir de ellos. En sintonía con la estética shandy que inspira su arte poética y con la comprensión de la obra literaria como una maleta donde cabe todo, la novela tal como la concibe el autor de Pasavento incorpora en su materia modalidades de escritura tales como el diario, la autobiografía, el autorretrato, la autoficción, la vida imaginaria y la crítica literaria. Este mestizaje, por otra parte, supone también un diálogo siempre interesante y fructífero con las tradiciones literarias en las que estos géneros se han desarrollado, así como con las culturas que las han acogido y transformado.

Entre las líneas de parentesco que es posible distinguir en los textos de Enrique Vila-Matas se encuentran aquellas que lo vinculan con dos tradiciones europeas que confluyen y se reconfiguran en América Latina y, de manera más específica, en Argentina y México: la del ensayo personal que resulta de la recomposición que los ingleses hacen del género creado por Montaigne y Bacon, y que se incorpora luego en la cultura literaria mexicana gracias a Pedro Henríquez Ureña, Alfonso Reyes y los ateneístas, por un lado; y la de las vidas imaginarias tal como las concibió Marcel Schwob y fueron adoptadas más tarde por Reyes, Torri y Arreola en México; y por Jorge Luis Borges y J. R. Wilcock, en Argentina.

En las líneas que siguen intentaré destacar, en primer lugar, los rasgos propios del género ensayístico que Enrique Vila-Matas ha incorporado a su poética novelística. En segundo lugar, trataré de mostrar de qué manera la absorción del espíritu y los principios estéticos de las vidas imaginarias forma parte de una idea del ensayo vinculada a la ficción y la trama, es decir, a dos rasgos que suelen 
asociarse con relatos y novelas más que con el ensayo y que, además, permiten al autor de Pasavento dotar a sus novelas de cierto dinamismo sin renunciar del todo al carácter reflexivo que domina en ellas. Como se verá, la integración de la vida imaginaria en la novelística de este autor es una manera de articular géneros referenciales como el ensayo, el diario y la crítica literaria, con la narrativa de ficción, y puede ser vista, al menos en parte, como una de las herencias más relevantes de Borges en la obra de Vila-Matas.

Quien alguna vez fuera definido como el más latinoamericano de los autores españoles (Quesada Gómez 2012: 623) comparte con escritores argentinos y mexicanos un pasado literario, una historia de afinidades y coincidencias estéticas que permiten considerarlo como parte de una historia literaria común que se ha fortalecido a través del tiempo. Sin dar por hecho que estamos ante una relación de influencia de un autor reconocido con respecto a escritores más jóvenes, señalaré algunas coincidencias que muestran el vigor, en dos jóvenes ensayistas mexicanos, de una idea del ensayo y de la novela como territorios permeables y abarcantes, y particularmente, con el arte poética de Enrique VilaMatas. Posiblemente, señalar las coincidencias entre estos tres autores nos permita, en otro momento, establecer vínculos entre las tradiciones reivindicadas por el novelista español, y ciertos rasgos de interés en el ensayo mexicano actual, tal como su tendencia a lo narrativo e, incluso, a lo novelístico.

\section{El ensayo en la obra de EnRique Vila-Matas}

El género ensayístico aparece de múltiples maneras en la obra de Enrique VilaMatas. Este hecho, que emerge como una evidencia al leer con atención cualquiera de sus textos, es reforzado por las abundantes reflexiones metaliterarias que encontramos en su obra narrativa y confirmado por la crítica especializada. Sus artículos y ensayos no solo se publican constantemente en la prensa internacional sino que son recopilados en libros, y la incorporación de elementos ensayísticos en su obra narrativa constituye un tema profusamente tratado por los narradores y personajes que habitan sus relatos. Relatos que, por otra parte, se comportan ostentosamente como ensayos, ante la mirada divertida, fascinada o desconcertada de sus lectores.

Los especialistas en el género advierten, sin embargo, que el término ensayo puede referirse a variedades textuales tan disímiles como pueden ser Las meditaciones del Quijote de Ortega y Gasset, El cazador de Alfonso Reyes o una tesis doctoral, por ejemplo. ${ }^{1}$ En este sentido, José María Pozuelo Yvancos zanja la cuestión al considerar dentro de esta categoría los textos que, por su forma y filiación, correspondan ya sea a los que dieron acta de nacimiento al género en

\footnotetext{
${ }^{1}$ Acerca de este asunto resulta esclarecedora la anécdota que J. M. Pozuelo Yvancos narra en "El género literario 'ensayo'" acerca de la variedad de textos que debieron evaluar los miembros del jurado de un Premio Nacional de Ensayo. "Lo que teníamos frente a nosotros", explica Pozuelo, "carecía realmente de unidad como clase de textos", pues convivían ante ellos monografías académicas, tratados y ensayos argumentativos, y ensayos personales o literarios (Cervera/Hernández/ Adsúar 2005: 179).
} 
el Renacimiento, o bien a los que estaban en el horizonte de reflexión de Lukacs, Max Bense o Theodor Adorno. Para el teórico español, además, importa que los textos puedan ser considerados como escrituras del yo, lo cual implica no solamente que lo personal sea la isotopía definitoria de su configuración discursiva sino también que sean textos escritos, y que en ellos exista una interdependencia entre las categorías de obra, autor y escritura. Pozuelo nota también que el ensayo está asociado a la libertad de juicio, siendo su rasgo más importante que en él se configure una tensión del discurso desde el autor, tensión en la que, además, prevalece "el tiempo del discurrir mismo" (Cervera, Hernández y Adsúar 2005: 179-191).

Autor de un estudio sobre los artículos y ensayos de Enrique Vila-Matas, Alfredo Aranda Silva pone el acento en el carácter "no sistemático, abierto a la digresión y, en según qué contextos, refractivo a la solemnidad científica", así como en la visibilidad del estilo y la poética del autor "en cuantas costuras o entrelazamientos internos ocupen el texto". Opuesta al carácter sistemático del texto académico, el ensayo surge de la libertad absoluta del juicio de un autor que ostenta en todo momento su presencia como tema central del discurso (Aranda Silva 2017: 71).

De estas consideraciones se desprenden dos rasgos fundamentales en la poética de Vila-Matas, siendo la primera de ellas esa omnipresencia que, independientemente de la figura que adopte la voz narrativa en el texto, tiene el autor. En este sentido, cabe recordar que según el escritor mexicano Álvaro Enrigue:

Vila-Matas no es un autor fantasma que se difumine detrás de lo que cuenta, sino un autor espectacular. Pertenece a la estirpe de Montaigne o Quevedo -una estirpe rara entre los autores de ficción. Lo que se escenifica en un libro de Vila-Matas no es una trama o una serie de ideas o una batalla contra el lenguaje, sino a Vila-Matas tramando, pensando o escribiendo bajo el avatar de un narrador. (Enrigue 2015)

Si la primera consideración está relacionada con la aparición o desaparición del autor que, como sabemos, es uno de los temas recurrentes de Vila-Matas, y un requisito del género ensayo literario -que requiere la presencia de un sujeto que escriba en primera persona y que responda por cada una de sus afirmaciones-, la segunda tiene que ver con otro de los asuntos que estructuran su poética: la libertad de juzgar y también de demorarse en digresiones, es decir, de transitar a su antojo por los aspectos más dispares de cualquier tema, es un elemento constitutivo del ensayo como género literario y es igualmente, como veremos enseguida, uno de sus tópicos más representativos.

Vale la pena recordar, en este sentido, que en un artículo aparecido hace años en Letras libres Enrique Vila-Matas compartía con sus lectores la emoción de haber recibido El arte de caminar (2004), uno de los títulos publicados dentro de la colección Pequeños Grandes Ensayos de la UNAM. El interés del citado volumen radica sobre todo en que en él se reúnen dos textos fundamentales de esa vertiente del género conocido como ensayo personal, informal o fami- 
liar, y que el propio Vila-Matas define en su artículo como la práctica "de temas aparentemente ligeros tratados desde la versión subjetiva de un autor que se dirige a sus lectores en primera persona del singular" (Vila-Matas 2005): "Dar un paseo" de William Hazlitt y "Excursiones a pie" de Robert Louis Stevenson .

Teselas fundamentales de uno de los temas más significativos de la tradición ensayística inglesa, los textos de Hazlitt y Stevenson recorren la analogía de la escritura como andanza placentera y sin rumbo fijo. Y, si bien es cierto que cada uno de los ensayos es una exploración individual -tal como el arte mismo de caminar que, como sostienen ambos autores, debe realizarse preferentemente en soledad-, el volumen deja claro que el ensayo nunca deja de ser una conversación y un encadenamiento sin fin de voces. Así parece verlo también Vila-Matas quien, lejos de limitarse a agradecer a su amigo Hernán Lara Zavala por haberle enviado el libro desde México, prolonga la línea esbozada por esos dos nombres y añade tres nombres a la estirpe de paseantes-escritores sugerida por el libro. Vale la pena notar que, tal como puede apreciarse en el siguiente fragmento, se trata de escritores ligados estrechamente a la poética del propio autor:

El tema del paseo nace ligero en Hazlitt, lo mantiene leve su discípulo Ste-
venson, se complica y se vuelve pesado con las meditaciones de Rousseau, lo
aligera y noveliza increíblemente Robert Walser, y W. G. Sebald lo convierte
en el género novelístico/ensayístico por excelencia de nuestro siglo. Y es que,
como decía Lichtencherg, la tendencia humana de interesarse en minucias ha
conducido a grandes cosas. (Vila-Matas 2005)

Cabe notar que la reflexión de Vila-Matas pone el acento en el cruce entre ensayo y novela efectuado por el escritor suizo -y emulado por él mismo-, y también que la mención de la levedad y a la ligereza obtenidas en el tema por Hazlitt, Stevenson y Walser conlleva el reconocimiento de una de las virtudes que Italo Calvino incluía en sus célebres Propuestas para el próximo milenio y que el autor español suele reivindicar con más ahínco en sus libros: la levedad. ${ }^{2}$

Encontramos en Doctor Pasavento una reflexión esclarecedora sobre ese vínculo sutil y poderoso que Vila-Matas reconoce entre el paseo, la levedad y la escritura. Según refiere el narrador, Carlo Levi interpretaba Tristam Shandy, obra construida casi en su totalidad con digresiones, como una fuga perpetua del punto final, de la muerte y del tiempo. Por su parte, Andrés Pasavento recuerda que esa novela siempre le pareció más bien un ensayo sobre la vida "tramado con un tenue hilo de narración, lleno de monólogos donde los recuerdos reales ocupaban muchas veces el lugar de sucesos fingidos, imaginados o inventados" (Vila-Matas 2006a: 45).

Una digresión, apunta el diccionario, consiste en romper el hilo del discurso y de introducir en él cosas que no tengan aparente relación directa con

\footnotetext{
${ }^{2}$ A partir de la clasificación establecida por Calvino, Vila-Matas afirma que mientras que Roberto Bolaño podría considerarse como un autor de la multiplicidad, él mismo caería más bien en el apartado de los escritores de la levedad (Vila-Matas 1999).
} 
el asunto principal (RAE 2017). Más allá de que las digresiones en la novela de Sterne huyan de la cuestión central y de esa línea recta que la lleva hacia su fin, queda claro que, al menos en el fragmento anterior, lo que parece impresionar más a Andrés Pasavento es que esta ruptura afecte sobre todo al hilo narrativo de la novela. Contrariamente a lo que pudiera pensarse, este alejamiento de la trama no representa una carga que entorpezca la lectura sino más bien un alivio para la obra, una liberación que le permite vagar y divagar, es decir, deambular con tanta soltura como hace un ensayo. Baste recordar lo que Montaigne decía, en clave de caminata, con respecto a su propio juicio:

A veces, lo paseo por un asunto noble y trillado, donde nada debe encontrar por sí mismo, pues el camino está tan desbrozado que no puede andar sino sobre huellas ajenas. Ahí su juego consiste en elegir la ruta que le parece mejor $y$, entre mil senderos, dice que este o aquel fue la mejor elección. Aprovecho cualquier argumento que me presenta la fortuna. Para mí son igualmente buenos. Y jamás me propongo tratarlos por entero. (Montaigne 2007: 437)

Cabe vincularlo luego con el siguiente pasaje donde Andrés Pasavento asocia su lectura de la obra de Sterne con una época triste, sí, pero también ligera y despreocupada con respecto al tiempo, a la cordura y a la muerte:

Triste y chiflado yo era. Mi vida estaba llena de saltos, de idas y venidas imprevistas, como la línea del pensamiento sinuoso de Sterne. Me acuerdo bien de que entonces la muerte todavía estaba escondida en los relojes. Ahora quien está escondido soy yo. Me acuerdo, me acuerdo muy bien de todo aquello. La vida era shandy. (Vila-Matas 2006a: 45)

Y, finalmente, recordar la manera en que el profesor Morante, especie de trasunto de Robert Walser en Doctor Pasavento, describe un microtexto que alguna vez había escrito sobre cierta carretera de Italia:

Y también sucedía, dijo, que durante mucho tiempo él había trabajado en un microtexto sobre esa carretera o, lo que venía a ser lo mismo, en un escrito que partía del comentario de esa película de Rosellini, sin saber adónde exactamente iría a parar su ensayo. Lo había terminado ese ensayo y seguía sin saber adónde le habían llevado sus palabras. Le gustaban, me dijo, ese tipo de microtextos que él ponía en marcha como si se tratara de un paseo errático en el que, en cualquier momento, si le apetecía, podía irse por las ramas, pues a fin de cuentas no sabía en ningún momento, en el terreno ensayístico, adónde se dirigía, suponiendo que fuera a alguna parte. (Vila-Matas 2006a: 102-103)

Resulta evidente que la descripción del microensayo de Morante traza el funcionamiento de la obra que lo contiene y también, al mismo tiempo, el de la escritura de Vila-Matas en su conjunto. Recordemos a este respecto que Pozuelo Yvancos ha dicho, por ejemplo, que el emblema de Historia abreviada de la literatura portátil es "carecer de dirección en el seno de un caos de asociaciones que impone su carácter libérrimo", ya que el ensamblaje de las acciones ahí referidas 
no obedece a la idea de necesidad (como ocurre en las novelas realistas) sino a la de azar o gratuidad, como ocurre con las asociaciones mentales (Pozuelo 2014: 267).

No es de extrañar, pues, que el tipo de ensayo que encontramos en la obra de Vila-Matas pueda compararse con un paseo, ni que la actitud de sus textos ensayísticos sea, como afirma Alfredo Aranda, la del Robinson, es decir, del flâneur. Este espíritu es también el que permitiría, según el estudioso, vincular al autor de Bartleby y compañía con otros ensayistas españoles como Julio Camba, Ramón Gómez de la Serna o Eugeni d'Ors (Aranda Silva 2016: 69).

Por otra parte, si atendemos lo que anotan Jordi Gracia y Domingo Ródenas de Moya, recordaremos que a diferencia de lo que ocurrió en otros países europeos la tradición del ensayo en España es discontinua por diversas razones, de modo que durante el siglo XIX, época en la que el género adquiere fuerza en países como Francia, Inglaterra o Alemania, el escenario ensayístico aparece como "ralo y decepcionante" (Gracia/Ródenas 2009: 15). No será sino hasta el siglo xx que el espíritu del ensayo informal tal como se desarrolló en el siglo xvı en Inglaterra, pudiera ser acogido en España "como un producto foráneo que, en medio siglo, el que va de 1890 a 1940, alentó una producción extraordinaria" en la que contribuyó enormemente el esfuerzo de Unamuno por conocer, traducir y emular a los ensayistas ingleses y estadounidenses (Gracia/Ródenas 2009: 25 y 27).

Este tipo de ensayo floreció en Inglaterra y en Estados Unidos con autores como Samuel Johnson, Johnathan Swift, William Hazzlitt, Charles Lamb, De Quincey, Robert Louis Stevenson, Oscar Wilde, Virginia Woolf, G. K. Chesterton, Waldo Emerson, William James o H. D. Thoreau, y que después sería recogido en España y en América Latina por autores como Miguel de Unamuno, Azorín, Alfonso Reyes o Julio Torri. En términos de Jordi Gracia y Domingo Ródenas, se trata de una tradición que recupera "el espíritu del ensayo montaigneano, la dicción familiar y hasta confidencial, la curiosidad inespecífica, la flexibilidad del discurso, el placer del merodeo alrededor de cualquier tema y hasta el sesgo humorístico" (Gracia/Ródenas 2009: 21).

Al señalar que Enrique Vila-Matas pertenece a la estirpe de los "narradores con vocación de ensayistas" que echan mano de utensilios literarios tales como recursos narrativos, metáforas o estrategias retóricas" como modelo de proceder en el desarrollo del pensamiento" (Aranda Silva 2016: 69), Alfredo Aranda destaca la colindancia que existe entre el relato y el ensayo y, lo que es más interesante en el contexto que nos ocupa, la posibilidad de incorporar en el ensayo recursos tales como la anécdota, la ficción y la figuración del autor, artilugios que, como es sabido, forman parte del estilo del autor de Doctor Pasavento.

Recordemos sobre este punto que, según ha señalado Liliana Weinberg, uno de los rasgos esenciales del ensayo es la responsabilidad que el autor tiene con respecto a sus afirmaciones, tal como queda expresado en la palabras iniciales de los Essais: "He aquí un libro de buena fe, lector". En un contexto que exigía a los tratadistas remitirse constantemente a la autoridad como única manera de respaldar sus afirmaciones, Montaigne postula el valor de su propio juicio y se 
compromete responder por todo lo que escribe, en un pacto de confianza, de autenticidad, veracidad y valor de lo dicho" (Weinberg 2001: 13). Para Weinberg, esta protesta de "correspondencia entre el proceso de indagación que se lleva a cabo y su versión en libro" constituye una clave del ensayo y convierte al género en un ejercicio de responsabilidad. "Todo ensayo lleva la firma de su autor y este deberá responder hasta sus últimas consecuencias por aquél", afirma Weinberg (15).

Pozuelo Yvancos, por su parte, entiende que, el hecho de que el ensayo sea una escritura del yo "no susceptible de ser ficcionalizada", y que se resista a que se separen las categorías de la enunciación y del autor, no significa que el escritor en tanto individuo histórico no pueda "velarse o metamorfosearse" tras la apropiación que el discurso hace de ella (2005: 188). Pozuelo advierte, por ejemplo, que la escritura ensayística de Vila-Matas rompe el molde de los géneros, en especial en lo referente a la contraposición inventado/ocurrido, y se pasa de lo verificable a lo ficcional de la manera que se describe a continuación:

Ocurre que sus artículos comienzan con frecuencia con el mismo dispositivo del que se ha servido luego en su obra ficcional Historia abreviada: parte de una breve anécdota personal, casi siempre autobiográfica precisa o posiblemente cierta [...] o creíble [...] y continúa elaborando a partir de esa circunstancia una amplificación que a menudo vierte como digresiones sobre lecturas ciertas, episodios semejantes presentes en la literatura o el cine, etc. Paulatinamente el artículo o ensayo se desliza por derroteros cuyo desarrollo lleva a construir, a partir de las sucesivas ampliaciones, verdaderas metamorfosis que lo llevan ya a un territorio totalmente ficcional. (Pozuelo Yvancos 2005: 156)

Si al orientarse a lo ficcional los ensayos de Vila-Matas transgreden las reglas del género, sus ficciones hacen lo propio al integrar, tanto en su forma como en su temática, la imbricación entre el autor y la escritura que postula el género ensayístico. Pozuelo expone así la manera en que este fenómeno se verifica en lo que él Ilama la "tetralogía metaficcional" del autor, que estaría conformada por Bartleby y compañía (2000), El mal de Montano (2002), París no se acaba nunca (2003) y Doctor Pasavento (2005):

La figuración del escritor en Vila-Matas, y esa es su peculiaridad, no es un asunto, antes bien es una forma, una estructura, un lenguaje, todo lo domina, y la mejor manera de trazar esa idea es hacer que coincidan la producción del significado y el texto mismo del que tal producción es objeto o consecuencia. De esa manera sujeto y objeto son indistinguibles. Tal es a mi juicio el principio dominante de la tetralogía del escritor y de la figuración del yo en Vila-Matas: él es un texto, sus narradores también lo son y ese texto es al que el lector asiste, creándose, en performance en el cual el escenario (la escritura) y su resultado (el texto) son una y la misma cosa. (Pozuelo Yvancos 2005: 182)

Encontramos, además, en toda la obra de Vila-Matas una figuración de la voz narrativa que opera en los distintos personajes a quienes se encarga una voz enunciadora y, por supuesto, aquella que es entendida "como forma de fantasear 
identidades complejas en las que el sujeto no es unitario sino que se quiebra en rostros, máscaras, personajes" (Pozuelo Yvancos 2005: 149).

Para centrarnos nuevamente en las estrategias narrativas a las que recurre el género ensayístico, invocaré aquí a Phillipe Lopate, quien recuerda que la frecuencia con la que el pronombre yo aparece en los ensayos personales no implica necesariamente que el lector sepa quién habla en el texto. Lo anterior hace necesario, según él, que el ensayista se construya un personaje del mismo modo que lo hacen los escritores de ficción: estableciendo patrones de hábitos y acciones, partiendo de las singularidades y extravagancias, la apariencia física y elementos característicos de la personalidad (Lopate 2013: s/p).

En el contexto de la poética de Vila-Matas, habría que entender esta construcción de personajes a partir de sí mismo dentro de la lógica de figuración a la que se refiere Pozuelo y, que como puede verse, lejos de contravenir el compromiso de responsabilidad al que alude Liliana Weinberg, lo lleva al límite, ya que la autenticidad que el texto ofrece solo se alcanza mediante antifaces, como dice Juan Villoro en el prólogo a De eso se trata:

Para quien escribe ficción, pasar al ensayo representa una forma menos solitaria de la lectura. Cuando un novelista explica su propia obra, suele ejercer una variante de la fabulación, en ocasiones más creativa que sus novelas. Ensayar sobre los otros ofrece una confrontación más indirecta pero más sincera: "Denle una máscara a un hombre y dirá la verdad", comentó Oscar Wilde. En este strip-tease al revés, las revelaciones llegan por lo que uno se pone encima. (Quesada Gómez 2012: 633)

Aunque en el texto citado Juan Villoro se refiere a su propia práctica ensayística, encontramos esta misma frase de Wilde en otro texto del escritor mexicano, esta vez a propósito de Vila-Matas:

Desde el título, Impostura revela uno de sus más socorridos recursos: la suplantación. El protagonista imita voces en busca de la suya, y cuando la obtiene, no le gusta. Paradoja de la autenticidad. La simulación se alza entonces como una forma más alta y creativa de la verdad. "Dénle a un hombre una máscara y dirá la verdad", escribió Wilde (el Pingüino complementa la idea en Batman regresa: "me encanta la franqueza de un hombre enmascarado"). (Villoro 2015)

Ya sea que se trate de un relato de ficción o de un ensayo personal o de crítica literaria, la función que Villoro confiere al travestismo como ejercicio de striptease al revés es un procedimiento recurrente en el autor de Aire de Dylan, y resulta profundamente significativo que, en este contexto, hablar de los demás, de la manera en que pueden hacerlo el crítico o el biógrafo, no sea en el fondo más que un rodeo para hacer lo que Montaigne dice querer conseguir con sus Essais: pintarse de cuerpo entero y, de ser posible, desnudo ((Montaigne 2007: 5). Este es, al menos, el sentido que le da el narrador de El mal de Montano a la escritura del "Diccionario del tímido amor a la vida", ese repertorio de los autores de diarios personales que más le han interesado a lo largo de muchos años, y 
que el protagonista emprende con el fin de "componer un retrato más amplio y curiosamente más fiel de mi verdadera personalidad, hecha en parte a base de los diarios íntimos de los demás" (Vila-Matas 2015a: 121).

Ejercicio de crítica literaria, este diccionario de diaristas es una muestra de ese parasitismo literario que, a lo largo de todo el libro, lleva al protagonista a compararse con un vampiro que subsiste y crece a costa de los demás. Siguiendo el ejemplo de Borges, a quien Alan Pauls atribuye una "estética de la subordinación", el narrador de El mal de Montano admite que su modus operandi no ha sido otro que el de buscar su estilo personal extrayendo la sangre de otros escritores para beneficio propio. "Yo encontré lo mío en los otros, llegando después de ellos, acompañándolos primero y emancipándome después" (2015: 127). Cabe subrayar que lo que este fragmento describe corresponde a la lógica del ensayo tal como lo concebía Montaigne, quien, como sabemos, construía sus Essais a medida que comentaba los libros que había leído, en un diálogo constante con sus autores preferidos.

\section{RAROS, EJEMPLARES E IMAGINARIOS}

Si examinamos de cerca ese autorretrato que Vila-Matas compone gracias a las vidas ajenas nos daremos cuenta-ayudados por el propio autor, quien no deja de señalarlo- de que todos los autores vampirizados tienen en común el ser escritores peculiares, extravagantes, vanguardistas o raros. "No busco, encuentro raros. $Y$ esos raros siempre tienen algo que ver -no escapa uno fácilmente de su destino- con la literatura", leemos en El mal de Montano (2015a: 58), en un guiño claro a una tradición que remite a Verlaine y a Darío, y que acaba conduciéndonos a Marcel Schwob, autor de Las vidas imaginarias y una de las figuras tutelares de Jorge Luis Borges.

Llegados a este punto, conviene atender el parentesco que el propio novelista ha trazado en sus textos y entrevistas con Marcel Schwob, a quien VilaMatas considera como un escritor único dotado de un estilo irrepetible y que, pese a no ser muy conocido, ha tenido una influencia enorme en autores tan importantes como Faulkner, Cunqueiro o Borges. El autor francés no solo está en el origen de muchas de las poéticas que nutren la estética del escritor catalán sino que funciona en sus textos como un prototipo del escritor singular y antirrealista que el mismo Vila-Matas busca ser, tal como se hace evidente en los elogiosos artículos que nuestro autor le ha dedicado.

En un claro afán por mostrar las coincidencias de su poética con la del autor francés, Enrique Vila-Matas destaca que el estilo de Marcel Schwob representó una oposición a la estética realista que predominaba en el siglo XIX específicamente a los postulados de Zola y a su idea de que el autor debía borrarse del texto. Lejos de desaparecer, sin embargo, el autor de Corazón doble convirtió su escritura en una celebración de la individualidad, la anomalía y la extravagancia de personajes marginales que, en muchas ocasiones, pueden leerse como reflejos de la figura del autor (Premat 2010). Vila-Matas admira también el hecho de que en una época fuertemente marcada por el positivismo y en pleno 
auge de la biografía con pretenciones cientificistas, Schwob entendiera que la imaginación podía ser una vía para el conocimiento de una persona (Vila-Matas 2015a).

En el retrato de Schwob que hace Vila-Matas en sus artículos resaltan igualmente su carácter extravagante y "móvil", ya que era un "maestro en fugas" $y$, algo muy importante, alguien capaz de emanciparse de su aspecto: "[Schwob] se fue a ver la tumba de su admirado Stevenson y, cuando volvió, jamás se había visto a alguien tan cambiado, y todo el mundo vio en Schwob a un hombre ya sin apariencia" (Vila-Matas 2011). Como puede verse, los rasgos del admirado autor francés son también los de muchos de los personajes de Vila-Matas, y aparecen igualmente en la autorrepresentación que el español realiza a partir de figuras modélicas tales como Walser o Kafka, por no citar más que algunos ejemplos. Se trata del mismo proceso de identificación que se verifica en la pregunta que da inicio a "Sobre todo lean a Schwob", y que bien podría referirse al propio VilaMatas: "¿Qué pensaríamos de alguien que estuviera escribiendo, por ejemplo, la historia imaginaria de la literatura contemporánea?".

Muy sugestiva resulta también la forma en la que nuestro autor bosqueja la tradición formada por los lectores y epígonos de Schwob, introduciéndose al mismo tiempo en ella. Antes de referirse a Borges, su alumno más celebre, VilaMatas recuerda que quince años antes de la publicación de Historia universal de la infamia "Schwob ya había tenido como herederos a los mexicanos Alfonso Reyes y Julio Torri, tocados como él por la gracia -tan poco habitual en la época- de la brevedad y la capacidad de síntesis" (Vila-Matas 2011). La mención de Alfonso Reyes, autor de Retratos reales e imaginarios, sería quizá un detalle episódico si Vila-Matas no precisara que el ensayista mexicano era maestro de Pitol, es decir, el autor que él reconoce como padre espiritual: "me convertí en escritor gracias a Pitol y mi afición definitiva por la cultura la produjo el propio Sergio" (Vila-Matas 2006b).

La permeabilidad de los límites entre lo real y lo imaginario, la oposición al realismo y el interés por lo singular y extravagante, entre otros, pueden considerarse como rasgos de esa tradición que se ha fortalecido de una forma imprevisible, ya que echó raíces muy lejos de la tierra que la vio nacer. La condición migratoria de esta tradición literaria es descrita así por Vila-Matas a partir de una observación del cuentista malagueño Cristian Crusat: "Así que puede hablarse [...] de una tradición literaria que, iniciada por un francés, se convirtió en latinoamericana por las intervenciones de primera hora de Reyes, Torri y Borges, para luego diversificarse por territorios literarios muy variados" (Vila-Matas 2017). Importa notar que la recepción de la obra del propio Vila-Matas no es ajena a este tipo de vicisitudes.

Por supuesto, la figura de Schwob está presente en el horizonte del VilaMatas gracias a Borges, pero también a autores tan relevantes para su formación tales como Gide, Faulkner, Tabucchi, Perec; y autores más recientes como Bolaño y Sophie Calle. Vale la pena observar que, según ha afirmado Julio Premat, las ramificaciones de esta tradición en la narrativa hispánica contemporánea son numerosas -el estudioso menciona como ejemplos a Roberto Bolaño, Mario 
Bellatin, Vila-Matas y Diego Vecchio- resultando especialmente perceptible el uso del género o subgénero llamado vida imaginaria o ficción biográfica como estrategia metaficcional para crear avatares del autor: ${ }^{3}$

En esa perspectiva, dentro de esa locura y marginalidad, cabe señalarse la recurrente representación de autores; esas variaciones barroquizantes y deformantes de vidas de escritores, que se sitúan a menudo del lado de la decadencia, la enfermedad, la anomalía, la amoralidad, lo monstruoso. La imagen del escritor como un ser extraño, necesariamente excéntrico sin ser extraordinario, es una característica fuerte [...]. Biografías de autores que funcionan como la degradación del modelo decimonónico, modelo que a su vez es una versión subalterna de héroes fundadores y de santos. Lejos de la heroicidad y el ejemplo, las prácticas actuales de las ficciones biográficas instauran una dinámica de descentramiento: de biografías, de métodos, de formas, de saberes, de Soñarse otro, verse en un espejo deformante, dibujar patéticas caricaturas: hay en todo esto una concepción del último héroe del mundo moderno, el escritor, visto desde la desvalorización y la incredulidad, desde la marginalidad y la impotencia, desde el vacío y la contingencia, todo lo cual es una manera de redefinir y desplazar nuestras concepciones actuales sobre el sujeto que escribe. (Premat 2010)

En primer lugar, la vida imaginaria de escritores -incluida la de él mismo- encuentra un lugar importantísimo en la escritura de Vila-Matas como materia prima para un autorretrato hecho de las biografías deformadas, ficcionalizadas y puestas en escena de autores admirados. En segundo lugar, las vidas incorporadas de esta forma en el magma vilamatasiano abonan un canon literario que crece y se fortalece en cada texto de nuestro autor. Parasitismo o vampirismo libresco, el ejercicio de la lectura productiva que Vila-Matas practica bajo la tutela de escritores como Borges o Walser, lo lleva a encontrar su propia parcela dentro del territorio vastísimo de la literatura -definiendo su propia poética a partir de la vida y la obra de otros-, pero también a elaborar un catálogo donde solamente encontraremos a los escritores modélicos que le permiten delinear una tradición y marcan las pautas de una estética personal.

Para Pozuelo Yvancos, las referencias del universo literario de Vila-Matas vinculan al autor con un tipo de novela y de escritura relacionadas "con la tradición de la modernidad, de las vanguardias narrativas: Robert Walser, Kafka, Musil, Valéry, Borges, W. S. Sebald son modelos que han realizado en sus obras una tradición de la que Vila-Matas se siente heredero y en íntima relación con

\footnotetext{
3 "En la literatura en castellano: Roberto Bolaño publica en 1996 un libro (La literatura nazi en América), de corte enciclopédico, que recopila biografías de escritores inexistentes que tienen alguna complicidad ideológica con el nazismo; Mario Bellatin, dedica un breve libro (a la vez biografía, bibliografía y abundante iconografía) a un escritor japonés inventado, cuya principal característica es su nariz descomunal (Shiki Nagaoka: una nariz de ficción, 2001), mientras que Enrique Vila-Matas recopila minuciosamente nombres y biografías de escritores que no escriben en Bartleby y compañía (2000), y un joven argentino, Diego Vecchio, cuenta en Microbios (2005) una serie de casos clínicos de enfermedades producidas por la literatura, enfermedades fabulosas y humorísticas que se producen en variados espacios culturales (Japón, Escandinavia, Bélgica, Estados Unidos, Argentina, Rusia, etc.)" (Premat 2010).
} 
la clausura que estos autores realizaron del ciclo de la novela realista" (Pozuelo Yvancos 2004: 266). Es en concordancia con esta estirpe que Vila-Matas ha elaborado un proyecto literario que, según Pozuelo, correspondería a la exégesis que el narrador de El mal de Montano hace de El castillo de Kafka:

... releo El castillo, novela infinita e incapaz de tener final, entre otras cosas porque en ellas el Agrimensor no viaja de un lugar a otro, sino de un comentario a otro. Se detiene el Agrimensor en todos los recodos del imaginario camino y lo comenta todo. Se diría que se dedica a escribir buscando llegar a las fuentes de la escritura, pero mientras tanto va comentando [...] el mundo. [...] Al contrario del Quijote, la novela de Kafka no tiene como asunto explícito el mundo de los libros -K. es agrimensor, no lector ni escritor-, y por tanto no tiene el mal de Montano ni se plantea problemas relacionados con la escritura, pero lleva esos problemas en su propia estructura novelesca, puesto que lo esencial de la peregrinación de $\mathrm{K}$. no consiste en desplazarse, sino en ir de una exégesis a otra, de un comentarista a otro, en escuchar a cada uno de ellos con atención apasionada, y luego en intervenir y en discutir con todos según un método de examen exhaustivo. (Vila-Matas 2015a: 170)

A partir de este pasaje del libro, Pozuelo afirma que, "para afirmarla o para negarla, Vila-Matas ha concebido su propio proyecto literario como un comentario al arte de la novela, entendida como una red de caminos trazados en el imaginario humano", un proyecto que rechaza "los principios de causalidad y de cierre de los proyectos del realismo" (Pozuelo Yvancos 2004: 265).

Tal proyecto literario sería, entonces, un texto que comentara el arte de la novela sin pretender convertirse en una y que debe entenderse como un paseo, lo cual nos remite nuevamente a la idea del ensayo como vagabundeo y digresión, pero también como una fuga en el sentido que el autor le da en su comentario a Sterne. Y ese recorrido sin fin ni dirección otra que no venga dictada por la asociación de ideas, dibuja una historia de la literatura figurada, puesta en escena y tan distorsionada como podría serlo una vida imaginaria. La puesta en abismo que encontramos en esa exégesis literaria que es El mal de Montano, muestra con claridad el aspecto del ideal novelístico de Vila-Matas, esta vez bajo la apariencia de uno de los consejos que Monsieur Tongoy da al protagonista para la elaboración de su conferencia:

2) Que mi conferencia fuera un microcosmos de lo que estoy escribiendo en Barcelona y que, por lo tanto, reuniera ensayo, memoria personal, diario, libro de viajes y ficción narrativa. Y que repitiera incluso la estructura de mi manuscrito barcelonés, pasando de la ficción a la realidad, pero sin olvidar nunca que la literatura es invención y que, como decía Nabokov, "ficción es ficción y calificar de real un relato es un insulto al arte y, la verdad, todo gran escritor es un gran embaucador". (Vila-Matas 2015a: 234)

Ensayo, conferencia, diario íntimo, diccionario biográfico, autorretrato y nouvelle autoficcional, El mal de Montano es una muestra del merodeo de Vila-Matas por el arte de la novela, y un ejemplo de ese texto leve, portátil y múltiple donde los 
géneros literarios se mezclan, y el sujeto asume que, al igual que la novela, ya no puede ser entendido como una unidad indivisible.

En este sentido, llama la atención que, como apunta Villoro, Vila-Matas desconfía de la noción misma de sujeto (Villoro 2015), el ensayo no solo confiere a los textos vilamatasianos su espíritu y sus principios estéticos, sino que sigue siendo -como quería Montaigne- una vía para la construcción de una identidad, por más confusa y fragmentada que esta sea. Como en el ensayo, además, la poética de Vila-Matas parece confiar la construcción -o la disgregación- de su identidad a la escritura, de modo que, finalmente, lo que pueda decirse sobre la novela puede definir también al sujeto que escribe: "No es pues la revelación de alguna verdad lo que mi diario anda buscando", explica el narrador de El mal de Montano, "sino la descripción cruda, clínica, de una mutación. Empecé mi diario siendo un narrador que añoraba ser un crítico literario, me fui después construyendo una personalidad de diarista [...] y ahora me veo transformado en un hambriento [...], un vagabundo..." (2015a: 226).

Así como el texto de Montano repudia las convenciones de la novela realista y el narrador se considera a sí mismo un "proyecto de identidad fragmentada" (208), el protagonista de Doctor Pasavento piensa que él mismo es un poema receloso ante la idea de identidad:

Debía estar contento yo de lo que era, feliz de ser un poema errante. Y luego me dije que el poeta que había escrito ese poema había perdido identidad en un vagabundeo infinito y hasta había perdido su nombre. En cuanto al poema, este decía que no hay identidades y que también las identidades son una carga pesadísima, y hablaba de paso de lo mucho que había que desconfiar de las ideologías que exaltan los méritos discutibles del concepto de identidad. (VilaMatas 2015a: 187)

\section{ENSAYO NARRATIVO, NOVELAS ENSAYÍSTICAS Y COLINDANCIAS MEXICANAS}

\subsection{Luigi Amara}

El panorama ensayístico de los últimos diez años en México está marcado por la percepción más o menos generalizada del hiato que separa dos vertientes del género: por una parte, el ensayo de largo aliento que aborda temas colindantes con la filosofía, la sociología y la política, y que puede leerse como parte de una reflexión colectiva sobre la identidad nacional; por la otra, el ensayo breve, con pretensiones artísticas, y cuyos temas -que con frecuencia tocan lo individual y lo íntimo-son menos importantes que el estilo de su escritura y el tono o la voz personal que el lector reconoce en él. Por otro lado, resulta relevante que mientras la primera categoría suele asociarse con el mundo académico, la disertación y la reflexión erudita, la segunda es considerada más como un acto creativo y artístico que como un ejercicio del pensamiento crítico.

Sin llegar a convertirse en un tema de gran trascendencia para las letras mexicanas -el ensayo no deja de ser un género minoritario- sí ha llegado, en cambio, a protagonizar algunas querellas interesantes tales como la que pudo 
leerse hace algunos años tras la publicación en Letras libres de "El ensayo ensayo" de Luigi Amara. En dicho texto, el poeta y ensayista Amara (Ciudad de México, 1971) definía el ensayo a partir de conceptos e imágenes recuperados de una tradición que va de Montaigne hasta Phillipe Lopate, pasando por Chesterton, de Quincey y Alfonso Reyes. El perfil que resulta de esta lectura es el de un género "irresponsable", propenso a la experimentación y a la exploración personal, definido principalmente por dos rasgos: su "acento subjetivo" y su "sinuosidad tanteadora" (Amara 2012a). Para el autor de El peatón inmóvil, el ensayo así entendido es el único que merece ser llamado con el nombre que le dio Montaigne al género, de modo que, en lugar de usar adjetivos como "literario", "personal" o "informal" para distinguirlo de la llamada "prosa de ideas" y de todo tipo de trabajos académicos -Amara asegura que la academia es uno de los principales enemigos del género-, se le llame simplemente "ensayo ensayo" (Amara 2012a).

Llama la atención, por otra parte, que, si bien el alegato de Luigi Amara parece ampararse en una concepción purista cuyo modelo es el mismo Montaigne, también reconoce que se trata de un género que sabe aprovechar todo tipo de modalidades discursivas y géneros literarios. Citando a Alfonso Reyes, en efecto, Amara dirá que en el "centauro de los géneros" hay de todo y cabe de todo porque, finalmente, el ensayo es el "hijo caprichoso de una cultura que no puede responder al orbe circular y cerrado de los antiguos, sino a la curva abierta, al proceso en marcha, al 'etcétera'" (Amara 2012a).

Sin embargo, más allá de su capacidad de absorber materiales diversos, lo que realmente constituye para Amara el rasgo determinante del ensayo es su carácter inventivo, lo cual contradice el lugar que la crítica le ha reservado al ensayo en la literatura de "no ficción", ya que, tratándose de un género de "imaginación reflexiva" o de "reflexión imaginante", las cosas tal como figuran en él "pueden o no haber tenido lugar" (Amara 2012a). Para un autor tan aficionado a los experimentos absurdos como Amara, resulta casi una obviedad afirmar que el ensayo es similar a la patafísica -movimiento cultural al que el autor no deja de referirse en su obra- porque ambos son ciencias de las soluciones imaginarias. De acuerdo con esta lógica, el ensayo sería "una falsa ciencia para problemas también a veces imaginarios" que, además, se ocupa de "una ficción suprema: que el yo puede conocerse a sí mismo" (Amara 2012a).

Para subrayar el papel que la imaginación ocupa en el género, Amara apuesta por hacer una depuración radical en su librero colocando al "ensayo ensayo" en los estantes reservados a la ficción y, en cambio, enviar a todos los usurpadores al estante de no ficción:

Para ahorrarnos más discusiones quién sabe cuán bizantinas, propongo que todos los ensayos espurios, de tipo político y de teoría literaria, los sociológicos y de actualidad económica que se refugian en la impersonalidad; que todos los tratados eruditos, académicos y la mayoría de los divulgativos que abogan por la formalidad, se queden en el estante de la "no ficción", allí donde se diría que lidian con la realidad o la representan. Y que el ensayo personal y tentativo se reubique en el estante de la ficción, en ese lado del librero en el que llanamente se amontona la literatura. (Amara 2012a) 
Aunque la comprensión del ensayo como un ejercicio de reflexión imaginante es perceptible en toda la obra de Amara, tal vez este hecho sea especialmente notable en tres de sus libros de ensayos: Sombras sueltas (2006), La escuela del aburrimiento (2012) y Los disidentes del universo (2013). Con temáticas que recuerdan algunas de las preocupaciones recurrentes al universo de Vila-Matas -la lectura como experiencia de habitar el pensamiento de otro individuo, la identificación física y mental de los protagonistas con sus autores favoritos, por no citar más que algunos-, los tres libros de Amara recurren a estrategias tales como la figuración del yo, el mestizaje de géneros y el uso de elementos ficcionales. En los tres, además, la cercanía con la vida imaginaria y, sobre todo en La escuela del aburrimiento, la propensión a explorar la confinidad con el género novelístico, resultan evidentes.

Sombras sueltas compila dieciséis ensayos sobre los escritores que le que importan a Amara y que, como si fuesen sombras, lo acompañan a todas partes, dándole cobijo, tranquilidad y compañía (Amara 2006: 12). Galería de autores raros a la que se suman también un pintor (Braque) y un comediante (Jerome Rothenberg), esta serie de semblanzas y reseñas literarias esboza una genealogía en cual Amara busca incribirse y, debido a esto, el conjunto puede leerse como un autorretrato y un ejercicio de exploración de sí mismo a partir de los antifaces que le ofrecen estas sombras.

Una de las afinidades permiten vincular a Amara con los personajes de Sombras sueltas es la identificación entre la escritura y el paseo. Esto acurre de manera evidente en el ensayo dedicado a Robert Walser, autor que, como hemos visto, "aligera y noveliza" el tema del paseo según Vila-Matas. Importa señalar que Amara no deja de mencionar al autor barcelonés cuando apunta que la fama de Robert Walser es mayor de lo que el mismo escritor suizo hubiera querido gracias al entusiasmo de admiradores tan célebres como Coetzee, Calasso o Vila-Matas, autor a quien Amara, a su vez, describe de la siguiente forma:

... un autor walseriano de cabo a rabo, tanto en sus preocupaciones como a veces en su dicción, que incluso se ha valido de Walser como "héroe moral" para construir una novela quizá demasiado propensa a la celebridad, ahora también premiada, lo que no deja de ser extraño tratandose de una defensa de la desaparición y de los personajes que gustan de avanzar en el vacío. (Amara 2006: 37)

Aunque ciertamente son rasgos que invitan a clasificar al autor de Jacob von Gunten como un escritor raro, ni su obsesión por desaparecer, ni su manía de escribir siempre con lápiz, ni su reclusión voluntaria en el manicomio de Herisau parecen ser los ejes medulares de la veneración que Amara siente por Walser. Sí lo son, en cambio, la libertad de su prosa miscelánea, el deseo de no llegar a ninguna parte, su talante errabundo y una convicción que, al menos tal como es formulada en Sombras sueltas, podría servir también para describir la poética del propio Luigi Amara: "La literatura entendida como paseo, y el paseo como única forma de vida" (2006: 44). 
En Los disidentes del universo, la simpatía de Amara por los personajes "rarísimos" (2013: 12) e improbables exhibe de manera aún más franca su filiación: tal como el autor señala en el prólogo del libro, los nueve personajes que protagonizan estos "ensayos conjeturales", como él los llama, se inscriben en la línea de las soluciones imaginarias de la patafísica -lo cual, como ya se ha visto, equivale a ratificar los textos como ensayos propiamente dichos-, pero también de las Vidas imaginarias de Schwob y Borges, de La sinagoga de los iconoclastas de J. R. Wilcock, y de Wakefield, ya que, al igual que ocurre en el célebre cuento de Hawthorne, el mecanismo de escritura de Los disidentes del universo consistió en imaginar a partir de un fragmento de realidad obtenido algún recorte de periódico, una conversación, una frase escuchada por ahí. La conjetura, en este sentido, se vuelve en estos textos un detonador eficaz para la reflexión pero también para el relato, pues casi todos los textos que integran el volumen rozan los lindes entre el ensayo y la ficción literaria. Se trata, por lo tanto, de ejercicios de "reflexión imaginativa", de "estampas reflexivas". Se trata, en suma, de ensayos.

Conviene detenerse un momento en el papel que el autor concede a la imaginación en un género que él mismo relaciona con el pensamiento. Al relacionar la escritura ensayística con esa ciencia de lo particular, de la excepciones y las soluciones imaginarias que es la patafísica, Amara inscribe su libro en una categoría de escritores marcados por su adhesión a la teoría que suscribe el movimiento cultural inspirado por Alfred Jarry. Me refiero a la Teoría de la equivalencia universal y de la conversión de contrarios, la cual afirma que lo verdadero se sostiene en lo falso del mismo modo que lo falso es engendrado por lo verdadero. A decir de Noël Arnaud, "sátrapa" del Colegio de 'Patafísica, una de las definiciones de dicha teoría se encuentra en "Una pequeña carta sobre los mitos" del Paul Valéry, la cual cito a continuación:

Es una especie de ley absoluta el que en todas partes, en todos los lugares, en
todo periodo de la civilización, en toda creencia, mediante cualquier disciplina,
y bajo todas las relaciones -lo falso soporta a lo verdadero; lo verdadero se
adjudica a lo falso como ancestro, como causa, como autor, como origen y
como fin, sin excepción ni remedio-, y lo verdadero engendra lo falso de lo que
exige haber engendrado él mismo. Toda antigüedad, toda causalidad, todo
principio de las cosas son invenciones fabulosas y obedecen a leyes simples.
(Valéry 1993: 240)

Entre los numerosos autores que, en algún momento, mostraron ser afines al espíritu patafísico se encuentran Marcel Schwob o Borges, por no citar más que aquellos que tanto Vila-Matas como Amara incluyen en sus respectivos cánones (Arnaud s/f). En todos estos artistas y escritores, en efecto, la imaginación no resulta un ingrediente ajeno a la reflexión sino, por el contrario, un camino que puede conducir a la verdad manera tan legítima como lo hace la ciencia.

Si los textos de Sombras sueltas hablan de Luigi Amara en voz baja, como parece sugerir la cita de Carnevali que sirve de epígrafe al libro, y los "rarísimos" de Los disidentes del universo son la imagen de lo que todos -incluido el propio 
autor- "pudimos ser y no hemos sido" (2013: 15), un reverso de ese mundo en el que todos vivimos y que "ya nos fatiga y damos por sentado y nos induce al aburrimiento o a la rutina" (2013: 15), La escuela del aburrimiento enfrenta este tedio del que huyen los prófugos de la normalidad.

Como explica el texto de su contraportada, esta obra da cuenta del enfrentamiento heroico del poeta y ensayista Luigi Amara con el Aburrimiento. Encerrado en su habitación y guiado por figuras tutelares como Pascal y Montaigne, el protagonista lleva a cabo una especie de recorrido iniciático por las obras que tratan el tema, para llegar, finalmente, a la conclusión de que "la lucha contra el aburrimiento es comparable al intento de aliviar la enfermedad de ser hombres" (2012: 279).

La escuela del aburrimiento es una obra miscelánea y, al mismo tiempo, está construida como un ensayo de largo aliento que podría también leerse como una novela ensayística. Escrita según un modelo afín a esa "maleta donde cabe todo" a la que se refiere Vila-Matas, la obra en cuestión integra reseñas de libros y datos biográficos de escritores como hiciera Cyrill Connoly en La tumba sin sosiego. Otras modalidades de enunciación que el texto recupera son el diario íntimo y la autoficción.

De manera parecida a como ocurre con las obras de Vila-Matas, es importante que el lector de Luigi Amara no pierda de vista que las anécdotas referidas pueden aceptar al menos dos tipos de acercamiento. Por un lado, las acciones de los personajes permiten una lectura literal en la cual todo lo dicho debe entenderse en sentido propio, lo cual suele confrontar al lector con situaciones absurdas, divertidas y, en ocasiones, francamente inverosímiles. Por otro lado, sin embargo, muchos pasajes escritos por el autor mexicano pueden entenderse en sentido figurado, lo cual franquea el paso hacia múltiples interpretaciones en clave metaficcional.

Un lector de Vila-Matas puede interpretar la obsesión que tiene el doctor Pasavento de disgregar su identidad y pasar inadvertido (Vila-Matas 2005: 217) como una parodia de la pretensión realista de "invisibilizar" al autor o, en lugar de ver simplemente al personaje como un raro, ver en él una imagen figurada del pensamiento sinuoso de una novela ensayo como La vida y las opiniones del caballero Tristram Shandy (2005: 45).

De igual forma, los peculiares experimentos que encontramos en obras como El peatón inmóvil o La escuela del aburrimiento pueden hacernos dudar de la buena salud mental del personaje llamado Luigi Amara, o sospechar que debemos recurrir a la acepción arcaica de la palabra ensayo y ver al ensayista como alguien que intenta hacer un experimento $y$, de esa forma, considerar su encierro iniciático como una puesta en escena del tipo de reflexiones suscitadas por el género ensayístico, así como una parodia de las convenciones asociadas a las escrituras del yo en general, como el supuesto de verdad y honestidad que suele atribuirse al diario o al propio ensayo personal.

Por otra parte, como ocurre en las novelas de Enrique Vila-Matas -a quien se alude en La escuela del aburrimiento al hablar de Perec y Walser (Amara 2012b: 276-277)-, encontramos en este libro de Amara un "discurso haciéndose" en el 
cual es posible reconocer una voz ensayística que convive armoniosamente con la narración, sin que sea fácil deslindar la anécdota de las ideas expresadas a partir de ella. De hecho, el propio autor parece sugerir que su libro bien podría leerse como se lee La montaña mágica de Thomas Mann, "una de las grandes novelas-ensayo sobre el aburrimiento" (2012b: 236).

Al igual que muchos de los libros de Vila-Matas, en realidad, La escuela del aburrimiento de Luigi Amara podría leerse como todos y cada uno de los modelos que ese ensayista, narrador y reseñista convoca en su obra. En los límites entre la ficción y la realidad, entre la anécdota y la reflexión, el relato iniciático y exploración del yo, La escuela del aburrimiento, como todo buen ensayo y como el ejercicio de reflexión imaginante que es, puede serlo todo.

\subsection{Valeria Luiselli}

Otra escritora que presenta afinidades con la poética de Enrique Vila-Matas, autor que ella cuenta entre sus coetáneos latinoamericanos (Luiselli 2014), es Valeria Luiselli (Ciudad de México, 1983). Esta joven novelista y ensayista no solo ha sabido asimilar los textos de Vila-Matas, sino que comparte con él una tradición que incluye a referencias como Salinger, Walser y Sebald, y a autores latinoamericanos como Pitol, Bolaño, Reyes y Borges. Con Enrique Vila-Matas entiende la novela moderna como un artefacto flexible, permeable, capaz de adoptar rasgos de otros géneros literarios tales como el ensayo, por ejemplo (Luiselli 2016).

La porosidad que permite el mestizaje genérico es uno de los rasgos representativos de los ensayos que conforman Papeles falsos (2010), hecho que no pasó inadvertido al propio Vila-Matas cuando, al presentar en Barcelona la primera novela de la autora, subrayó el papel relevante que el tema del paseo cumple en ambos textos. Para él, la prosa de Luiselli recuerda a Robert Walser porque "pone en escena la lógica del pensamiento, que va avanzando como a trompicones y va de un lado a otro" (Luiselli/Vila-Matas 2011).

Presentado en el texto de la cuarta de forros como "una serie de ensayos narrativos de temas diversos", Papeles falsos fue ubicado por algunos en una zona indefinida entre el ensayo, la crónica y la novela autobiográfica. Por un lado, la prominencia del yo como sujeto de la enunciación y tema principal del libro, remite a las convenciones del ensayo personal. Por otro lado, las numerosas anécdotas relatadas por la voz enunciadora revela ese talante narrativo que llevó a David Miklos a definir la obra como "novela autobiográfica":

Realizada la lectura, consumado el paso de la primera a la última página, Papeles falsos se descubre como un libro de igual modo rebelde a los géneros: no es mero ensayo, pero tampoco es Ilana crónica: no. Lo que Luiselli ha pergeñado y pulido con esmero en esta primera entrega libresca es una suerte de novela autobiográfica a la vez velada y evidente, oculta tras las cortinas casi traslúcidas de la literatura en estado puro. (Miklos 2010)

Aunque la apreciación del novelista mexicano pase por alto que los textos de Luiselli se inscriben plenamente en la tradición del ensayo informal-que, como 
se ha visto, no excluye ni la anécdota ni la ficción-, es verdad que en este libro resulta particularmente evidente un proceso figurativo por el cual la ciudad, la escritura y la voz autoral se fusionan en una unidad indivisible que filtrará la trama de su primera novela, revelando los rasgos más interesantes de su poética.

En este sentido, conviene notar la expresión "papeles falsos" que da título al primer libro de la autora alude a la obtención del documento amañado que permitió a la escritora acceder gratuitamente a los servicios médicos venecianos. Tema del último ensayo del libro, esta anécdota da pie a Luiselli para auto figurarse como una combinación de rasgos verdaderos y ficticios pues, aunque la autora tiene realmente un pasaporte italiano gracias a la nacionalidad de su abuelo, la historia que ella cuenta a las autoridades sobre su supuesta unión libre con el chico veneciano es falsa. Con todo, es gracias a esta mistificación que Luiselli se salva no solo de la enfermedad, sino de la fatalidad de poseer una patria única y verdadera (Luiselli 2010: 106).

La idea de que falsificación puede ser una vía de acceso a enunciaciones más plenas de la verdad estructura toda la obra de la autora, rigiendo tanto la representación del espacio como de la identidad nacional. En Papeles falsos, la ciudad es una entidad fragmentaria que solo adquiere sentido gracias a la mirada que la recorre. Y, así como la ciudad revela su forma solo a medida que la protagonista camina o pedalea por sus calles, orientada por las palabras de Brodsky o Benjamin, la escritura de la autora es moldeada según la imagen de la ciudad horadada en la que vive.

En el ensayo titulado "Relingos", Luiselli reflexiona sobre los espacios residuales que, en ciertas zonas de la ciudad de México, sobreviven a una larga historia de demoliciones y reconstrucciones urbanas. Estos "retazos" o "piezas sobradas de un rompecabezas" (2010: 73) otorgan una fisonomía particular a la ciudad y la convierten, a los ojos de la autora, en una especie de rostro fragmentado:

En el Paseo de la Reforma, soberbia faz que simula la entrada a una ciudad de México imperial que desde luego ya no existe, hay un cuadrángulo de pequeñas ausencias, de plazuelas donde hubo algo que ahora son solo huecos. Como si a la sonrisa perfecta y señorial de la Madame de la Reforma le faltaran ahora algunos dientes. (Luiselli 2010: 73)

Más adelante, la serie de aforismos sobre la escritura que cierra este mismo ensayo recupera la imagen de los relingos para definir ya no un elemento urbano sino los entresijos de la escritura y del oficio de escribir. Vista a la luz de las artes arquitectónicas, la escritura se convierte en un proceso comparable a la restauración de edificios en la medida en que escribir es "rellenar relingos". Pero si el prosista, que según Luiselli tiene "espíritu de albañil", trabaja "a partir de las fisuras y los huecos", es precisamente porque su trabajo consiste también en confeccionar esos relingos. Escribir, dice también Luiselli, es "taladrar paredes, romper ventanas, dinamitar edificios" (2010: 78-79). 
Por último, en otro de los ensayos, la autora vuelve a la metáfora de los relingos, esta vez para describir su propio rostro, lleno de relingos tras una noche de sueño:

\begin{abstract}
Despierto con el rostro incompleto. Algo le pasó a mi cara durante la mudanza. Como si entre tanta caja se me hubiera perdido la línea de la frente; como si con tanto polvo se me hubiera difuminado la curva de la barbilla. Me estudio en el espejo del baño mientras me cepillo los dientes y trato de conectar la nariz con el entrecejo, el ojo derecho con su ojera irremediable, siempre más oscura que la del lado izquierdo: tengo un rostro lleno de huecos. (Luiselli 2010: 84)
\end{abstract}

Los relingos vuelven a aparecer en Los ingrávidos, novela gobernada por las ideas complementarias de la demolición y la recomposición. En términos generales, la obra pone en escena un proceso de creación autoficcional protagonizado por una autora que trata de restaurar los recuerdos fragmentarios de la época en la que vivió en Nueva York y, al mismo tiempo, contar un suceso imaginario de la vida del poeta y diplomático mexicano Gilberto Owen a partir de ciertos pasajes de su correspondencia. No es irrelevante observar que, para describir a Owen, Luiselli convoca al poeta Tomás Segovia, quien ha dicho de él que toda su obra es una "transmutación poética de la materia biográfica" (Luiselli 2009).

Entre los detalles verificables de la vida de Owen que Luiselli incorpora en su propia novela destaca su obsesión por pesarse todos los días. En Los ingrávidos se muestra a un poeta consciente de pesar un poco menos cada día, proceso cotidiano hacia la ingravidez que se relaciona con el "afantasmamiento" al que, según la novelista, son sometidos los seres de la vida real a medida que se transforman en voces de su libro (2011a: 21-22).

Entendida como una mixtura de realidad y ficción, la obra literaria es simbolizada en Los ingrávidos por el árbol seco que la narradora encuentra abandonado en la azotea del edificio neoyorkino donde vivió Owen y que ella recoge al encontrarle cierto parecido con una maceta que el poeta menciona en sus cartas. A medida que la escritora va pegando en él post-its con toda la información fragmentaria que encuentra e imagina sobre el poeta, el árbol seco adquiere un follaje renovado tal como ocurre con esas vidas incompletas o anodinas que cobran vida gracias a la imaginación de escritores como Schwob, Vila-Matas y la propia Luiselli.

No está de más notar, por otra parte, que entre las modelidades de escritura que conviven en el libro se encuentra un diario donde la narradora anota el progreso de su novela y comenta sucesos de su vida familiar. Cada vez que ella escribe, ya sea ahí o en la novela, su marido la interroga sobre el grado de veracidad de sus palabras. Y, cuando la narradora hace decir a su personaje autoficcional que su esposo está empacando para irse a Filadelfia, donde seguramente lo espera una amante, su esposo le pregunta, indignado, por qué miente sobre él, que ni piensa viajar ni tiene amantes. "Para que pase algo", responde ella (2011: 89). 
La respuesta de la escritora de Los ingrávidos recuerda, por ejemplo, ciertos pasajes de Vila-Matas como aquel episodio de El mal de Montano en el que el protagonista provoca una discusión con su esposa para aportar "una pequeña dosis de rabiosa actualidad" a su diario (Vila-Matas 2002: 55). La adulteración del diario es recurrente también en Amara, autor que, en "Para una arqueología de los desperdicios", cuenta cómo fingió escribir un diario tan honesto como el de Pontormo cuando, en realidad, controló los resultados de su experimento cambiando radicalmente sus hábitos para no tener que dar cuenta en su diario de la mediocridad y escasa originalidad de su basura (Amara 2003: 113).

\section{A MODO DE CONCLUSIÓN: OTRAS RESONANCIAS Y NUEVOS DERROTEROS DEL ENSA- YO EN MÉXICO}

Enrique Vila-Matas, que alguna vez fue considerado como un escritor extravagante y minoritario en España y, un poco menos, en Hispanoamérica, es hoy en día un referente incuestionable en el ámbito de la literatura actual escrita en castellano. Lejos de poner en evidencia la influencia directa que la obra del autor barcelonés ejerce en los autores jóvenes mexicanos, los dos ejemplos que he examinado en estas páginas dan cuenta de una serie de afinidades, tradiciones compartidas y estrategias discursivas comunes entre quienes, en México, exploran nuevos derroteros del ensayo y la novela, y un escritor que se ha ganado a pulso la carta de identidad latinoamericana.

Las visicitudes de géneros y subgéneros como el ensayo personal y la vida imaginaria constituyen dos buenos ejemplos de la manera en que las tradiciones literarias se forman y se reinventan gracias a la apropiación que los escritores llevan a cabo mediante las experiencias paralelas del viaje y la lectura. Vila-Matas, que se reconoce como heredero de figuras tan representativas de la literatura hispanoamericana como son Jorge Luis Borges, Sergio Pitol y Alejandro Rossi, y que encuentra afinidades entre ellos y el ensayo informal que se implantó en México a principios del siglo $\mathrm{xx}$, propicia a su vez nuevas reformulaciones de esos legados en autores más jóvenes que, además, han descubierto caminos literarios inusitados gracias a la continua reflexión literaria que el autor de El viaje vertical lleva a cabo en sus libros.

Entre los ensayistas que, en México, dicen tener algún tipo de cercanía con la poética de Enrique Vila-Matas y que, además, figuran entre los autores de la sección titulada "La vida de los otros" del sitio web del escritor español, están Antonio Ortuño, quien ve en él a "uno de los pocos autores españoles de su generación que ha establecido un intenso diálogo con las literaturas y plumas latinoamericanas desde una postura despojada de arrogancia" (Ortuño 2015); Juan Villoro, quien lo define como "una figura articuladora de tradiciones dispares", destacando en él su capacidad para asimilar voces ajenas y resignificarlas en contextos insólitos (s/f); y Guadalupe Nettel, quien ve en sus libros "un paradigma de esa nueva literatura que se inclina por géneros híbridos", y dueño de un "estilo omnívoro que todo lo convierte en literatura: las biografías propias y ajenas, las anécdotas literarias, el periodismo, la música, las escenas callejeras 
y hasta las frases sueltas que el autor escucha durante sus trayectos en autobús" (Nettel $s / f)$.

Tal vez a Enrique Vila-Matas, tan interesado en desaparecer, le ocurra algún día lo mismo que a Marcel Schwob o a Robert Walser: la celebridad de sus lectores y epígonos volverá más visible su figura. Y, lejos de pasar inadvertida, su voz no podrá sino ser también cada vez más audible en la medida en que resuena en la voz de sus cofrades trasatlánticos.

\section{OBRAS CITADAS}

Amara, Luigi (2006): Sombras sueltas. México, UNAM /Equilibrista.

— (2012a): "El ensayo ensayo", Letras libres, n. ${ }^{\circ} 158$, pp. 22-27.

- (2012b): La escuela del aburrimiento. México, Sexto Piso.

- (2013): Los disidentes del universo. México, Sexto Piso.

Aranda Silva, Alfredo (2016): La escritura articulística y ensayística de Enrique Vila-Matas. La crítica de un escritor. Tesis doctoral inédita. Universitat de Barcelona. En línea: <http://diposit.ub.edu/dspace/bitstream/2445/107831/1/AAS_TESIS.pdf> [última consulta: 31.10 .2017$]$.

Arnaud, Noël (s/f): "Pataphysique". En Encyclopæedia Universali. En línea: <http://www.universalis/fr/encyclopedie/pataphysique> [última consulta: 29.06. 2018].

Castro Hernández, Olalla (2016): "El sujeto escindido y la renuncia a la novela como totalidad (Escritura fragmentaria e hibridación genérica en la narrativa de Enrique VilaMatas)", Signa. Revista de la Asociación Española de Semiótica, n. 25, pp. 471-493.

Enrigue, Álvaro (2015): "Celebración de Vila-Matas", El Universal. En línea: <http://www. eluniversal.com.mx/entrada-de-opinion/articulo/alvaro-enrigue/cultura/letras/2015/09/12/celebracion-de-vila-matas> [última consulta: 29.10.2017].

Gracia, Jordi, y Ródenas, Domingo (eds.) (2015): Pensar por ensayos en la España del siglo $x x$. Bellaterra, Ediciones UAB.

Hazlitt, William, y Stevenson, Robert Louis (2004): El arte de caminar. México, UNAM.

Lopate, Phillipe (2013): To Show and to Tell. The Craft of Literary Nonfiction. Nueva York, Free Press.

Luiselli, Valeria (2010): Papeles falsos. México, Sexto Piso.

- (2011a). Los ingrávidos. México: Sexto Piso.

- (2011b): "Recorridos", La Central. En línea: <https://www.lacentral.com/ recorridos/?idr=99811> [última consulta: 31.10 .2017 ].

— y Vila-Matas, Enrique (2011): "Los ingrávidos de Valeria Luiselli: postit 1", <https:// vimeo.com/25242008>.

_ (2014): "Me gustaría ser como Salinger, pero siempre es tarde para desaparecer", Abc. En línea: <http://www.abc.es/cultura/cultural/20141110/abci-valeria-luiselli-daranhablar-201411041247.html> [última consulta: 31.10.2017].

_ (2016): "La novela moderna es un género flexible", Sur blog. En línea: <https://surblogspot.wordpress.com/2016/06/21/valeria-luiselli-la-novela-moderna-es-ungenero-flexible/> [última consulta: 31.10.2017]. 
Miklos, David (2010). "La historia secreta de los mapas", Crítica. Revista cultural de la Universidad Autónoma de Puebla, 26 de agosto. En línea: <http://criticabuap.blogspot. mx/2010/08/la-historia-secreta-de-los-mapas.html> [última consulta: 31.10.2017].

Montaigne, Michel de (2007): Los ensayos (según la edición de 1595 de Marie de Gournay). Barcelona, Acantilado.

Nettel, Guadalupe (s/f): "Mis pasos hacia Enrique Vila-Matas o el paraíso Bartleby", <http://www.enriquevilamatas.com/escritores/escrnettel2.html> [última consulta: 31.10.2017].

Ortuño, Antonio (2015): "Una excepción", <http://www.enriquevilamatas.com/escritores/ escrortunoa1.html> [última consulta: 31.10 .2017 ].

Pozuelo Yvancos, José María (2004): Ventanas de la ficción, narrativa hispánica, siglos xx y xxı. Barcelona, Península.

— (2005): "El género literario 'ensayo'". En Vicente Cervera, Belén Hernández y María Dolores Adsúar (eds.): El ensayo como género literario. Murcia, Universidad de Murcia.

- (2010): Figuraciones del yo en la narrativa. Javier Marías y E. Vila-Matas. Valladolid, Universidad de Valladolid.

Premat, Julio (2010): "Monstruos, infames y criminales. Ficciones biográficas, de Schwob a la actualidad", Lecciones doctorales (Universidad de Antioquia), 40 pp. En línea: $<$ https://www.academia.edu/5716072/Monstruos_infames_y_criminales._Vidas_ imaginarias_de_Marcel_Schwob_a_la_actualidad> [última consulta: 29.10.2017].

Quesada Gómez, Catalina (2012): "Ensayistas en fuga. Nuevas y ampliadas regiones del ensayo mexicano actual", Revista Iberoamericana, pp. 623-636.

Real Academia Española (2017): http://dle.rae.es/ [última consulta: 31.10.2017].

Valéry, Paul (1993): "Una pequeña carta sobre los mitos". En Paul Valéry: Estudios filosóficos. Madrid: Visor, pp. 233-241. Tr. Carmen Santos.

Vila-Matas, Enrique (1999): "Bolaño en la distancia", Letras Libres. En línea: <http:// www.letraslibres.com/mexico/libros/bolano-en-la-distancia> [última consulta: 31.10.2017].

_ (2005): "Pasear y pensar", Letras libres. En línea: <http://www.letraslibres.com/mexicoespana/pasear-y-pensar> [última consulta: 29.10.2017].

_ (2006a): Doctor Pasavento. Barcelona, Anagrama.

(2006b): "Me hice escritor gracias a Pitol", La República. En línea: <http://prod.larepublica.pe/tendencias/273431-vila-matas-me-hice-escritor-gracias-a-pitol> [última consulta: 31.10 .2017$]$.

_ (2011): "Marcel Schwob hacia Samoa", El País, 5 de julio. En línea: <https://elpais.com/ diario/2011/05/07/babelia/1304727198_850215.html> [última consulta: 31.10.2017]

- (2015a): El mal de Montano. México, Seix Barral.

_ (2015b): "La voz viva de Marcel Schwob", El País, 14 de diciembre. En línea: <https:// elpais.com/cultura/2015/12/14/actualidad/1450121078_675418.html> [última consulta: 30.10 .2017$]$.

(2017): "Sobre todo lean a Schwob", El País. En línea: <https://elpais.com/cultura/2017/03/16/babelia/1489669037_997181.html> [última consulta: 30.10.2017].

(s/f): "Lo que dije de Rossi en Barcelona", Revista dossier, n. ${ }^{0} 9$. En línea: <http://www.revistadossier.cl/lo-que-dije-de-rossi-en-barcelona/> [última consulta: 30.10.2017]. 
Villoro, Juan (2015): "Vila-Matas, la escritura desatada", <http://www.enriquevilamatas. com/escritores/escrvilloro1.html> [última consulta: 31.10.2017].

Weinberg, Liliana (2001): El ensayo, entre el paraíso y el infierno. México, UNAM-FCE. 